\title{
The prevalence of overuse injuries in Australian non-elite netballers
}

This article was published in the following Dove Press journal: Open Access Journal of Sports Medicine

\author{
Lianne Bissell ${ }^{1,2}$ \\ Peter Lorentzos ${ }^{1,2}$ \\ 'School of Medicine, University of \\ Dundee, Dundee, UK; ${ }^{2}$ Department \\ of Orthopaedics, Westmead Hospital, \\ Sydney, NSW, Australia
}

Purpose: The aim of this study was to investigate the prevalence of overuse injuries in non-elite netballers and whether these increase over a typical competitive season and to establish if player age, experience, training, and use of bracing are related to overuse injuries.

Patients and methods: A prospective study was conducted over a 12-week period, using a recently developed questionnaire. Data were collected on overuse injuries in the knee, ankle, and shoulder areas every week.

Results: Thirty-seven players responded to the questionnaire, with an average response rate of $65 \%$. The total prevalence of overuse injuries identified was $52.7 \%$, with ankle problems accounting for $26 \%$ (75 cases), knee problems accounting for $21.2 \%$ (61 cases), and shoulder problems accounting for 5.5\% (16 cases). Ankle injuries increased over the study period, while knee and shoulder problems decreased. Injuries were more common in players over 36 years old or those with less than 5 years of playing experience. Players who used a brace were more likely to have an overuse complaint. Training volume was not associated with increased risk. Conclusion: Overuse injuries are common in netballers, particularly of the knee and ankle. Shoulder overuse complaints are higher than previously reported. Risk factors for injury include older age and less playing experience, and these should be considered when planning injury prevention programs for this sport.

Keywords: sports, injury, risk, prevention

\section{Introduction}

Netball is played by over 20 million people worldwide ${ }^{1}$ and is the number one team sport in Australia ${ }^{2}$ with 649,000 participants in 2010. ${ }^{3}$ Playing netball requires rapid acceleration and deceleration and sudden changes in direction. Therefore, it is not surprising that injuries occur, particularly in the lower extremity. A systematic review found that ankles were most commonly injured, closely followed by knees. ${ }^{4}$ Overall, injuries from netball are the seventh most common cause of sports-related emergency department presentations in Australia. ${ }^{5}$

The incidence of netball injuries has been reported as high as $30.1 \%$ of players. ${ }^{6}$ Of all presentations to an Australian Sports Medicine Center over a 12-month period, netball was the third highest cause of sports-related injuries. ${ }^{7}$ Even at the elite level, injuries occur in over $25 \%$ of players. ${ }^{8}$ Players aged between 30 and 40 years are thought to be at the highest risk, with the occurrence of one injury for every 40 players, ${ }^{9}$ although others have found injury to be highest in 26-30-year-old players. ${ }^{10}$
Correspondence: Lianne Bissell Australia

Tel +6I 4 I6I65466

Email lianne.b@hotmail.com.au 
Little is known about overuse injuries in this sporting population, even though they account for $14 \%$ of all netball injuries. ${ }^{11}$ Overuse injuries are defined as "those without a single, identifiable event responsible for their occurrence". ${ }^{12}$ They occur as a result of accumulated stress to tissues such as ligaments, bones, and tendons. While the specific tissues and anatomical sites involved vary from one individual to another, the cause is the same, repeated episodes of microtrauma surpassing the body's ability to repair. ${ }^{13}$

Lower extremity overuse injuries are described as "inflammation, stress fracture or tendinitis of the knee, patella, lower leg, ankle, heel or foot". ${ }^{14}$ Netball requires players to suddenly change direction, rapidly accelerate and decelerate and jump and land, and make all movements that require eccentric muscle contractions and can result in microtears of tendons. It is very easy to visualize the numerous ways in which an overuse injury could occur in the lower extremities of netballers. Elite netballers attributed poor landing techniques as the primary cause of injury during games, ${ }^{8}$ and research demonstrates that a player's landing technique is the biggest influence of musculoskeletal stress. ${ }^{15}$ Many players will wear protective braces during training sessions and games. They are thought to provide greater stability to joints by reducing muscle activity during landing without affecting biomechanics. ${ }^{16}$

Netball also involves repetitive overhead actions in throwing or intercepting balls. Most of the upper limb injuries sustained in netball involve the hand, wrist, or forearm and only $0.5 \%$ of injuries involve the shoulder. ${ }^{17,18}$ However, many sports involving similar actions, eg, volleyball and softball, record shoulder overuse injuries as a common complaint. ${ }^{19-21}$ There have also been reports of joint sprains and rotator cuff inflammation among basketball players. ${ }^{22}$

Studies in runners have shown an increase in overuse injuries with higher training times or duration. Shin splints were more common in runners who trained more than four times per week or more than $2,600 \mathrm{~km}$ in total, while more experienced runners had an increased risk of Achilles tendinopathy. ${ }^{23}$ In netball, injuries are more frequent in higher competitive levels, eg, A-grade. ${ }^{17}$ Given that A-grade players spend more time in training and, therefore, potentially have an increased risk of overuse injuries may explain this finding. Contrary to this hypothesis, one study discovered that training for 4 hours or more per week was shown to be protective of injury in non-elite netball players, although in this study they did not differentiate between traumatic and overuse injuries. ${ }^{13}$ Certainly, the prevalence is high among elite players, for example, of those players competing in the 1988 Australian Netball Championships, more than 25\% sustained overuse injuries. ${ }^{24}$

The aim of this prospective study is to evaluate the prevalence and severity of overuse injuries in non-elite female netball players in Sydney, Australia. No previous similar studies have been identified from the current evidence base so this study presents a unique opportunity to establish a platform for identifying players at risk and designing injury prevention programs.

\section{Patients and methods Participant selection}

All netball players registered to a local all-female amateur netball club were contacted by email and invited to participate in the study. Of the 98 members contacted, 37 members accepted with written informed consent. This study was approved by the University of Dundee's Research Ethics Committee.

\section{Data collection procedure}

Every Sunday for the duration of the main competitive season (12 weeks), participants were sent an email linking them to an Internet-based questionnaire on overuse injuries. If no response had been received, a reminder email was sent 4 days later.

\section{Questionnaire}

The Oslo Sports Trauma Research Center questionnaire, ${ }^{25}$ which can be applied to find overuse injuries in any anatomical area, was used. A sample of this is found in Figure S1. This tool was developed and validated in 2012. The focus of this study was on the knee, ankle, and shoulder based on the available literature regarding common netball injuries or injuries from similar sports (eg, basketball). ${ }^{26}$

There were four questions for each anatomical area that covered symptoms, and the consequences of these upon training volume, performance and pain during play. The possible symptoms for each anatomical area were outlined before starting the questions so that there was no ambiguity.

In addition to the injury-focused questions, participants were asked to state their training hours (to nearest hour) and use of a brace or strapping (for each anatomical area) every week. Multiple-choice options were given for players to select their age group (less than 25, 26-30, 31-35, 36-40, and $41+$ years) and total years of experience playing netball (less than 1, 1-5, 6-10, and 11+ years). 


\section{Prevalence calculations}

Prevalence was calculated by dividing the number of participants reporting any overuse problem by the total number of respondents and was calculated overall and weekly. Overall prevalence was calculated by adding all players who reported at least one overuse injury during the study period and dividing by the total number of participants in the study. The term "significant problems" refers to those overuse injuries that led to reduced participation or inability to participate.

\section{Severity score}

A severity score of $0-25$ was calculated for each question, and the four questions were summated to give a score from 0 to 100 for each anatomical area. This score allows an independent measure of the consequences of an overuse injury in terms of its effect on sports-related performance, reduction in training, and pain. A score of 0 represents no problems, the higher the score the more severe the associated consequences, with 25 being the maximum. This method of scoring allows whole number scores by equally balancing the middle response scores.

\section{Statistical analysis}

The data were analyzed using the SPSS Version 22.0 for Windows. Pearson coefficient correlations were used to determine how the prevalence of overuse injuries varied over time. Chi-squared tests were used to assess the relationship between overuse injuries and player's age, experience, training volume, or use of bracing.

\section{Results}

\section{Overuse injuries}

The overall prevalence of overuse injuries identified in this study was $77.7 \%$, with $25 \%$ of players reporting significant overuse injuries, causing enough symptoms to reduce or prevent participation. If only lower limbs are considered, the overall prevalence decreased to $75 \%$ with $25 \%$ significant injuries. A breakdown by anatomical area is seen in Table 1 .

\section{Knee overuse injuries}

A total of 61 cases of overuse injuries of the knee were reported over the 12 weeks by 17 players. Ten of these cases (four players) had either moderate or severe symptoms. The prevalence of knee overuse injuries over time is seen in Figure 1.
Table I Overall prevalence and average severity score of overuse injuries by anatomical area

\begin{tabular}{|l|l|l|l|}
\hline & Knee & Ankle & Shoulder \\
\hline Overall prevalence (\%) (all problems) & 47.2 & 47.2 & 22.2 \\
\hline $\begin{array}{l}\text { Overall prevalence (\%) (significant } \\
\text { problems) }\end{array}$ & 11.1 & 19.4 & 2.7 \\
\hline Average weekly severity score $(x / 100)$ & $31.8 \mathrm{I}$ & 32.74 & 15 \\
\hline
\end{tabular}

There is a trend for the prevalence of knee overuse injuries to diminish over the season. However, this correlation was not statistically significant $(R=-0.535, P=0.073)$.

In cases identified as overuse injuries, $55.7 \%$ had to reduce training volume as a result of their knee problems while $60.7 \%$ felt that their performance had been affected by the same problems. As a result of netball over the course of the study, $88.5 \%$ had experienced at least minor knee pain.

Severity scores for these 61 cases were calculated. The average severity score for training volume was $6.4 / 25$, the average severity score for performance was $6.04 / 25$, and the average severity score for pain was $9.36 / 25$. Coupled together with the average score for prevalence (10.01/25) means the severity of knee overuse injuries in this study was $31.81 / 100$.

\section{Ankle overuse injuries}

A total of 75 cases of overuse injuries of the ankle were reported over the 12 weeks by 17 players. Seventeen of these cases (seven players) had either moderate symptoms or severe symptoms. The prevalence of ankle overuse injuries over time is seen in Figure 2.

The figure demonstrates a trend for ankle overuse injuries to increase over the course of the season. However, this relationship is not statistically significant $(R=+0.545, P=0.068)$.

About $44 \%$ of players had to reduce training volume as a result of their ankle problems while $50.7 \%$ felt that their performance had been affected by the same problems.

As previously stated, severity scores for these 75 cases were calculated. The average severity score for training volume was $6.53 / 25$, the average severity score for performance was $6.92 / 25$, and the average severity score for pain was $7.8 / 25$. Coupled together with the average score for prevalence (11.49/25) means the severity of ankle overuse injuries in the current study was $32.74 / 100$.

\section{Shoulder overuse injuries}

A total of 16 cases of overuse injuries of the shoulder were reported over the 12 weeks by eight players. One of these 


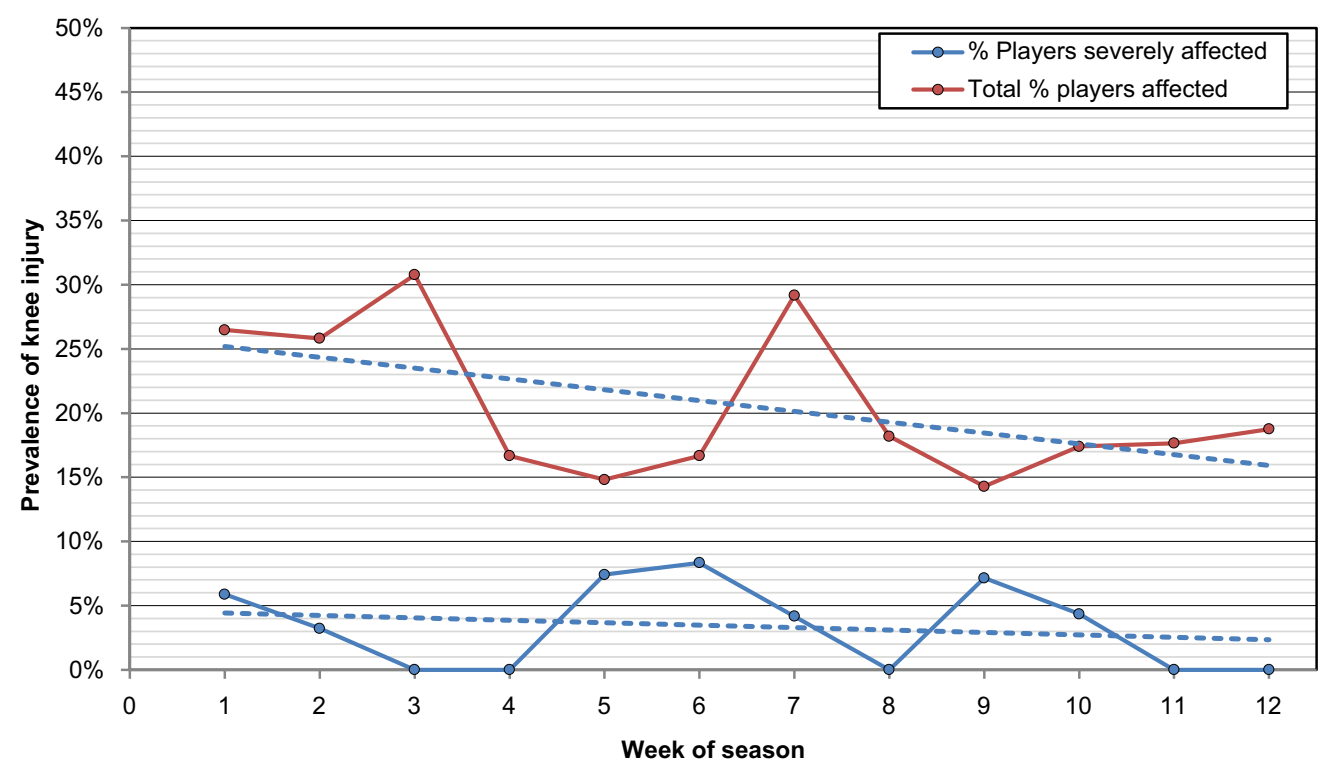

Figure I Prevalence of knee overuse injuries over the study period.

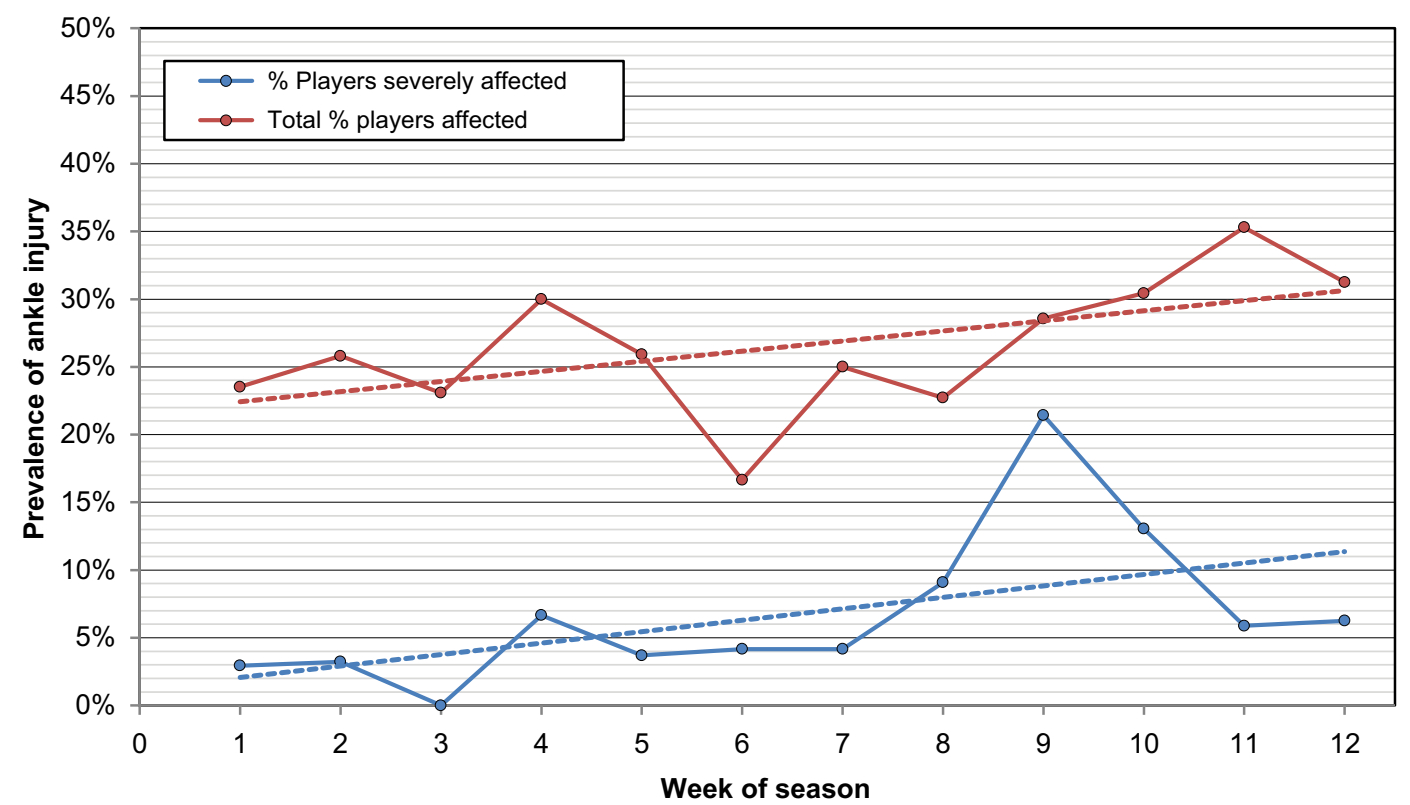

Figure 2 Prevalence of ankle overuse injuries over the study period.

cases had severe symptoms. The prevalence of shoulder overuse injuries over time is seen in Figure 3.

There were no reported cases of shoulder problems in the last 2 weeks of the season. Shoulder problems were only considered significant in week 12; for the remainder of the study, they were reported as minor only. Due to the scarcity of data, $95 \%$ CI could not be determined.
The prevalence of shoulder injury decreased over the course of the study and is statically significant $(R=-0.0658, P=0.02)$.

Of those with overuse injuries, $31.3 \%$ had to reduce training volume as a result of their shoulder problems while $50.3 \%$ felt that their performance had been affected by the same problems. As a result of netball over the course of the study, $56.3 \%$ had experienced at least minor shoulder pain. 


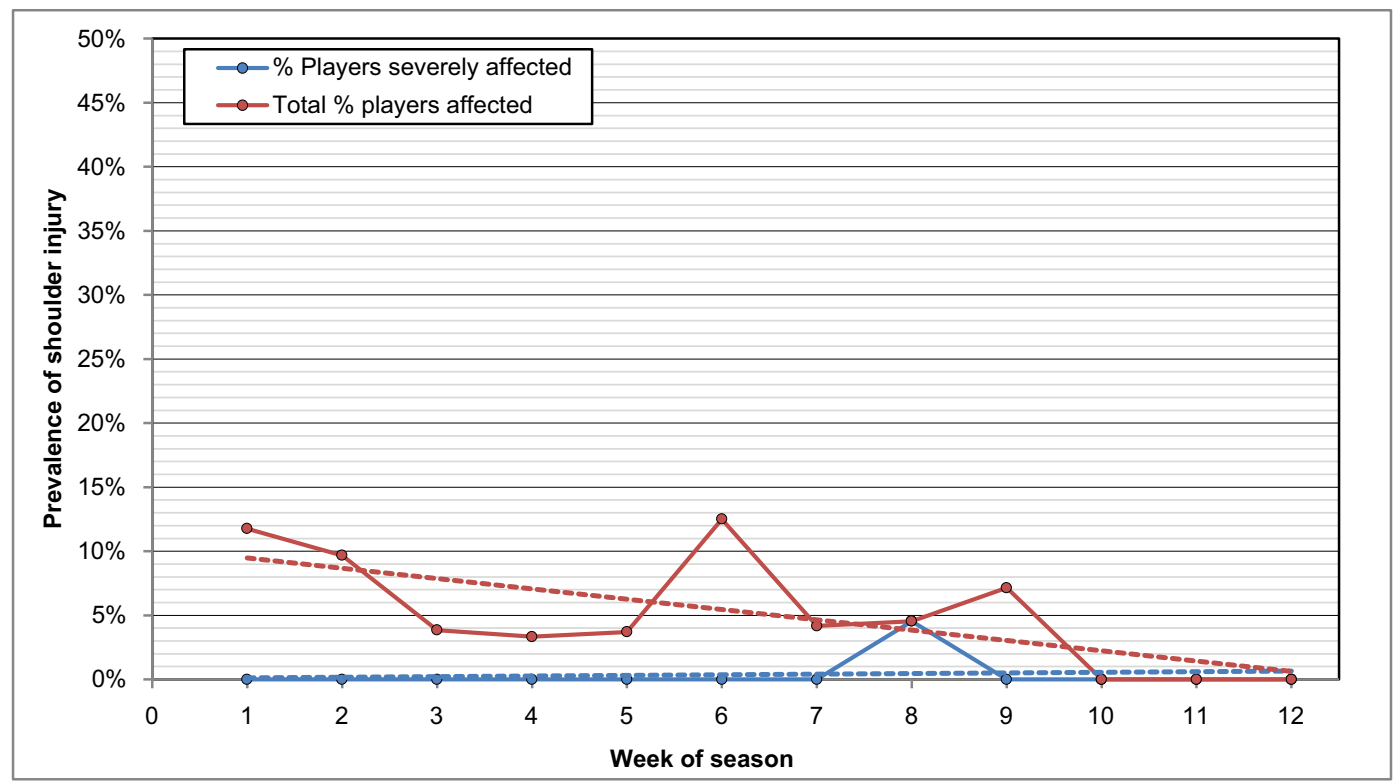

Figure 3 Prevalence of shoulder overuse injuries over the study period.

As previously stated, severity scores for these 16 cases were calculated. The average severity score for training volume was $1.75 / 25$, the average severity score for performance was $2.92 / 25$, and the average severity score for pain was 3.58/25. Coupled together with the average score for prevalence $(6.75 / 25)$ means the severity of shoulder overuse injuries in the current study was $15 / 100$.

\section{Effect of age on overuse injuries}

The largest percentage of players fell in the age group of $26-30$ years (35.1\%), and no player was over 45 years. Each anatomical area had a different age group with the highest prevalence of overuse injuries as demonstrated in Figure 4. Knee problems were highest in the age group of $41+$ years and lowest in the age group of 31-35 years. Ankle problems were most common in 31-35-year olds and lowest in 41+year olds. Finally, shoulder problems were more prevalent in 36-40-year olds and least so in 41+-year olds.

The prevalence of knee and ankle injuries in players over 36 years is significantly more than those under 35 years (knee: $\chi^{2}[1, \mathrm{~N}=288]=8.027, P=0.005$; ankle: $\chi^{2}[1, \mathrm{~N}=288]=22.172$, $P=0.000)$.

\section{Effect of experience on overuse injuries}

Most had been playing netball for more than 11 years (61.1\%). As no one in the study had played for less than 1 year, this category was removed from analysis. Unsurprisingly, those with the least experience (1-5 years) had the highest injury rate in every anatomical area, as shown in Figure 5.

Those with 6 or more years of experience had significantly less knee problems than those with 5 years or less $\left(\chi^{2}[1\right.$, $\mathrm{N}=288]=812.108, P=0.001)$. Similarly, those with 11 or more years of experience have significantly less knee problems than those with 10 years or less $\left(\chi^{2}[1, \mathrm{~N}=288]=5.997, P=0.014\right)$.

Ankle problems are only significantly more common in those with 5 or less years of experience $\left(\chi^{2}[1, \mathrm{~N}=288]=5.96\right.$, $P=0.015$ ).

\section{Effect of bracing on overuse injuries}

Even with knee strapping or supportive bracing, $92.3 \%$ of those players still reported a knee problem over the 12 weeks. In contrast, only $59.6 \%$ of those using ankle straps or braces reported ankle problems. No participant in this study used shoulder strapping or braces.

Interestingly, players who use a support have significantly more overuse problems than those who do not (knee: $\chi^{2}[1$, $\mathrm{N}=288]=41.258, P=0.000$; ankle: $\chi^{2}[1, \mathrm{~N}=288]=88.187$, $P=0.000)$.

\section{Effect of training on overuse injuries}

Overuse injuries of the knee and ankle were highest in those players whose total training volume was between 4 and 5 hours per week. Shoulder overuse injuries were common when players trained for less than 1 hour per week. 


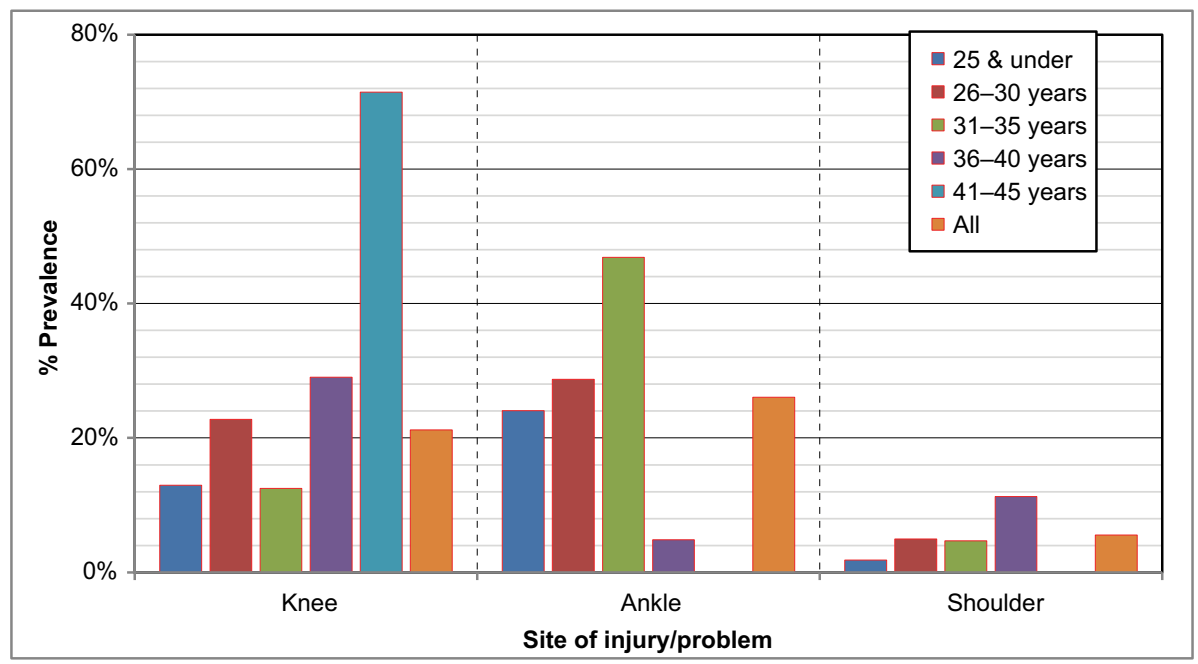

Figure 4 Prevalence of overuse injuries by age group.

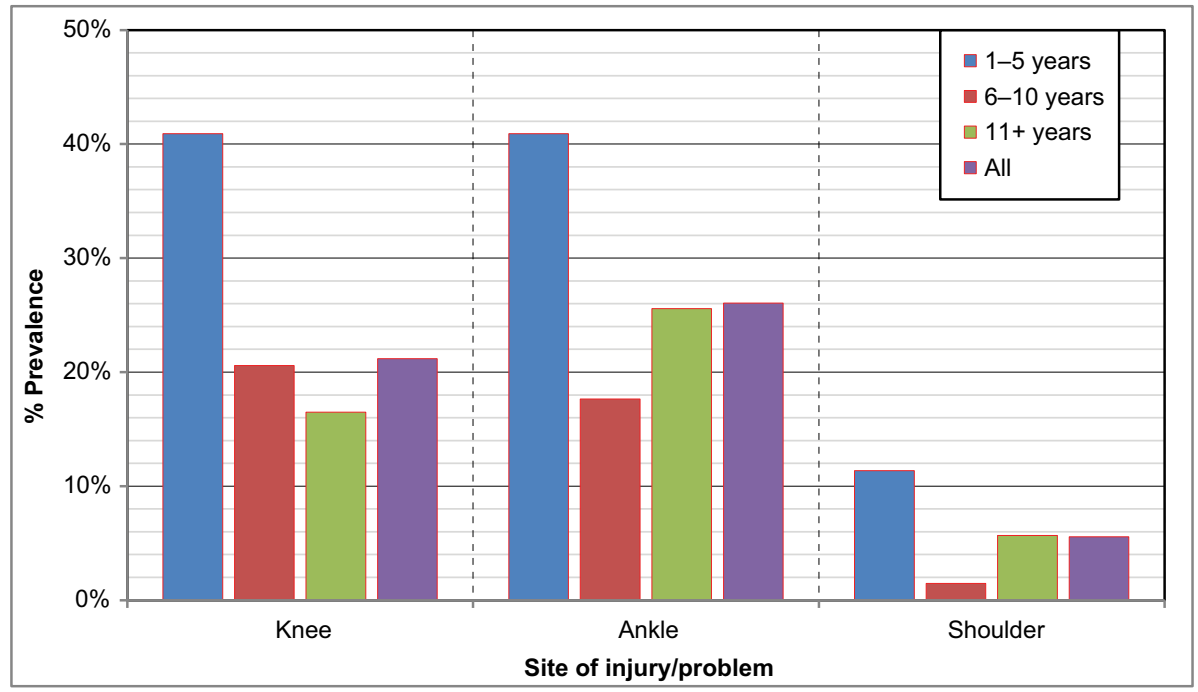

Figure 5 Prevalence of overuse injuries by the length of playing experience.

No statistically significant differences in the prevalence of overuse injuries were found between knees, ankles, and shoulders when the training time was compared.

\section{Discussion}

This study is, based on the current available literature, the first of its kind looking exclusively at overuse injuries in non-elite female netball players. The highest reported injury prevalence rate of injuries in netball in the current literature is $30.1 \%{ }^{6}$ Given that overuse injuries were identified in $77.7 \%$ of this study cohort, overuse injuries should be majorly considered in designing injury prevention programs.
One of the main findings of this study was that lower limb injuries were more prevalent than upper limb injuries, which supports the premise that netball is a "game prone to knee and ankle injuries", ${ }^{22}$ more specifically that ankle overuse injuries were more common than knee problems. This agrees with multiple studies. ${ }^{4,17,26}$ A multisport study in Western Australia found that ankle injuries were almost twice as common as knee injuries. ${ }^{11}$ However, they did not differentiate between acute and overuse injuries. The incidence is vice versa in similar sports. ${ }^{27}$

Despite the lack of literature on upper limb overuse injuries in netball players, it is still surprising to see the data on shoul- 
der overuse injuries in this study. The results are conflicting; shoulder problems accounted for $12 \%$ of all overuse injuries identified, but there were a number of weeks when no shoulder problems were reported and on only one occasion was a shoulder problem reported to be serious. Despite the above comments the prevalence of shoulder injuries is the same as identified in studies looking at volleyball players ${ }^{28}$ and 11 times higher than the same injury in studies with netball players. ${ }^{17}$

Acute injuries often occur in the first 4 weeks of the season. ${ }^{10}$ In this study, there was a spike in knee problems at week 5 , ie, after 4 weeks of consecutive playing, which may be a contributing factor. If an overuse injury is "characterized by a mechanism of gradual onset and an underlying pathogenesis of repetitive micro trauma" 29 there should be an increase in these injuries over the course of the season. This trend was seen in ankle injuries but the overall trend was for knee and shoulder injuries to decrease over the study period.

There were a number of significant findings in this study, which could be used to develop sport-specific injury prevention programs. For instance, both knee and ankle injuries were more common in less experienced players and those aged 36 years or over. This contradicts one study, which found that young elite players were more at risk of injury. ${ }^{30}$ However, other studies agree that players aged over 30 years are at the greatest risk. ${ }^{9}$

Interestingly, those players who used strapping or bracing for knee or ankle joints had significantly more overuse injuries. It is difficult to establish the cause and effect here though. Are joint supports causing more overuse injuries or are those who are prone to overuse injuries more likely to use a brace? Literature suggests that bracing can have a protective effect on landing in netball. ${ }^{16}$

\section{Strengths}

The major strength of this study is its uniqueness, hence contributing to the current evidence base on overuse injuries in netball. Existing research has either focused on overuse injuries in other sports or in those focusing on netball that has not differentiated between acute and overuse injuries. This study clearly demonstrates a high prevalence of overuse injuries within the netball population and suggests that further research is required.

\section{Limitations}

This study does have limitations. First, the questionnaire used relies on a players' self-reporting of problems under a very general definition of what is considered a "problem" and therefore overuse injury. This can lead to an over- reporting due to players not differentiating between true overuse injuries vs acute injuries or normal post-game pain, eg, delayed onset muscle soreness. As the questionnaire was designed and validated on elite athletes and this study was focused on amateur players, it may not be truly transferable. Future studies should amend the symptom information in the description sections of the questionnaire to account for the level of education amateur players having about different types of injuries. This issue has been acknowledged by the designers of the questionnaire. ${ }^{25}$ However, acute injuries can become chronic overuse type injuries either of the involved joint or of the related joint as a consequence of compensation. The sample size was a convenient sample of female netballer who agreed to participate in the study. Further research should look at collecting actual medical diagnoses to investigate how one injury may influence the other and to ensure that acute injuries are not included in the prevalence calculations, leading to falsely high results.

Finally, as the study was designed on research in similar sports in order to preselect the anatomical areas (knee, ankle, and shoulder), it could be that other areas were missed, despite it being a potential common site of overuse injuries in netball players.

\section{Disclosure}

The authors report no conflicts of interest in this work.

\section{References}

1. International Federation of Netball Associations. About IFNA. Available from: http://www.netball.org/about-the-inf-organisation-effectivegovernance-administration. Accessed August 15, 2014.

2. Finch $\mathrm{C}$, Cassell E. The public health impact of injury during sport and active recreation. J Sci Med Sport. 2006;9(6):490-497.

3. Australian Sports Commission. Participation in Exercise, Recreation and Sport: Annual Report. Canberra, Australia: Standing Committee on Recreation and Sport; 2010.

4. Fong DT, Hong Y, Chan LK, Yung PS, Chan KM. A systematic review on ankle injury and ankle sprain in sports. Sports Med. 2007;37(1):73-94.

5. Finch C, Ozanne-Smith J, Williams F. The Feasibility of Improved Data Collection Methodologies for Sports Injuries. Australia: Monash University Accident Centre; 1995.

6. Cunningham $\mathrm{C}$, Cunningham $\mathrm{S}$. Injury surveillance at a national multisport event. Aust J Sci Med Sport. 1996;28(2):50-56.

7. Baquie $P$, Brukner P. Injuries presenting to an Australian sports medicine centre: a 12-month study. Clin J Sport Med. 1997;7(1):28-31.

8. Singh P, Mansingh A, Palmer W, Williams EW. Injuries in elite Jamaican netballers. West Indian Med J. 2013;62(2):118-121.

9. Otago L, Peake J. The role of insurance data in setting priorities for netball injury prevention strategies. J Sci Med Sport. 2007;10(2):105-109.

10. Stevenson MR, Hamer P, Finch CF, Elliot B, Kresnow M. Sport, age, and sex specific incidence of sports injuries in Western Australia. Br J Sports Med. 2000;34(3):188-194.

11. Mcgrath AC, Ozanne-Smith J. Attacking the Goal of Netball Injury Prevention: A Review of the Literature. Australia: Monash University Accident Research Centre; 1998. 
12. Yang J, Tibbetts AS, Covassin T, Cheng G, Nayar S, Heiden E. Epidemiology of overuse and acute injuries among competitive collegiate athletes. J Athl Train. 2012;47(2):198-204.

13. Herring SA, Nilson KL. Introduction to overuse injuries. Clin Sports Med. 1987;6(2):225-239.

14. Dick R, Hertel J, Agel J, Grossman J, Marshall SW. Descriptive epidemiology of collegiate men's basketball injuries: National Collegiate Athletic Association Injury Surveillance System, 1988-1989 through 2003-2004. J Athl Train. 2007;42(2):194-201.

15. Steele JR. Biomechanical factors affecting performance in netball. Implications for improving performance and injury reduction. Sports Med. 1990;10(2):88-102.

16. Hopper DM, Mcnair P, Elliott BC. Landing in netball: effects of taping and bracing the ankle. Br J Sports Med. 1999;33(6):409-413.

17. Hopper D, Elliott B, Lalor J. A descriptive epidemiology of netball injuries during competition: a five year study. $\mathrm{Br} J$ Sports Med. 1995a;29(4):223-228.

18. Smartt P, Chalmers D. Obstructing the goal? Hospitalisation for netball injury in New Zealand 2000-2005. N Z Med J. 2009;122(1288):62-75.

19. Verhagen EA, van der Beek AJ, Bouter LM, Bahr RM, van Mechelen W. A one season prospective cohort study of volleyball injuries. $\mathrm{Br} J$ Sports Med. 2004;38(4):477-481.

20. Briskin SM. Injuries and medical issues in softball. Curr Sports Med Rep. 2012;11(5):265-271.

21. Bonza JE, Fields SK, Yard EE, Dawn Comstock R. Shoulder injuries among United States high school athletes during the 2005-2006 and 2006-2007 school years. J Athl Train. 2009;44(1):76-83.
22. Starkey C. Injuries and illnesses in the national basketball association: a 10-year perspective. J Athl Train. 2000;35(2):161-167.

23. Knobloch K, Yoon U, Vogt PM. Acute and overuse injuries correlated to hours of training in master running athletes. Foot Ankle Int. 2008;29(7):671-676.

24. Hopper D, Elliott B. Lower limb and back injury patterns of elite netball players. Sports Med. 1993;16(2):148-162.

25. Clarsen B, Myklebust G, Bahr R. Development and validation of a new method for the registration of overuse injuries in sports injury epidemiology: the Oslo Sports Trauma Research Centre (OSTRC) overuse injury questionnaire. Br J Sports Med. 2013;47(8):495-502.

26. Mckay GD, Payne WR, Goldie PA, Oakes BW, Stanley JJ. A comparison of the injuries sustained by female basketball and netball players. Aust J Sci Med Sport. 1996;28(1):12-17.

27. Cumps E, Verhagen E, Meeusen R. Prospective epidemiological study of basketball injuries during one competitive season: ankle sprains and overuse knee injuries. J Sports Sci Med. 2007;6(2):204-211.

28. Bahr R, Reeser JC, Fédération Internationale de Volleyball. Injuries among world-class professional beach volleyball players. The Fédération Internationale de Volleyball beach volleyball injury study. Am J Sports Med. 2003;31(1):119-125.

29. Roos KG, Marshall SW. Definition and usage of the term "overuse injury" in the US high school and collegiate sport epidemiology literature: a systematic review. Sports Med. 2014;44(3):405-421.

30. Hopper DM, Hopper JL, Elliott BC. Do selected kinanthropometric and performance variables predict injuries in female netball players? $J$ Sports Sci. 1995;13(3):213-222. 


\section{Supplementary material}

\section{Oslo Sports Trauma}

\section{OSTRC Overuse Injury Questionnaire}

\section{Part 1: Knee Problems}

Please answer all questions regardless of whether or not you have problems with your knees. Select the alternative that is most appropriate for you, and in the case that you are unsure, try to give an answer as best you can anyway.

The term "knee problems" refers to pain, ache, stiffness, swelling, instability/giving way, locking or other complaints related to one or both knees.

Question 1

Have you had any difficulties participating in normal training and competition due to knee problems during the past week?

\section{Full participation without knee problems}

Full participation, but with knee problems

Reduced participation due to knee problems

$\square \quad$ Cannot participate due to knee problems

\section{Question 2}

To what extent have you reduced you training volume due to knee problems during the past week?
No reduction
$\square \quad$ To a minor extent
$\square \quad$ To a moderate extent
To a major extent
$\square$ Cannot participate at all

Question 3

To what extent have knee problems affected your performance during the past week?
No effect
To a minor extent
To a moderate extent
To a major extent
Cannot participate at all

\section{Question 4}

To what extent have you experienced knee pain related to your sport during the past week?
No pain
Mild pain
Moderate pain
Severe pain

Figure SI OSTRC Overuse Injury Questionnaire.

Note: Adapted from Clarsen B, Myklebust G, Bahr R. Development and validation of a new method for the registration of overuse injuries in sports injury epidemiology: the Oslo Sports Trauma Research Centre (OSTRC) overuse injury questionnaire. Br J Sports Med. 2013;47(8):495-502.' 


\section{Reference}

1. Clarsen B, Myklebust G, Bahr R. Development and validation of a new method for the registration of overuse injuries in sports injury epidemiology: the Oslo Sports Trauma Research Centre (OSTRC) overuse injury questionnaire. Br J Sports Med. 2013;47(8):495-502.

\section{Publish your work in this journal}

The Open Access Journal of Sports Medicine is an international, peer-reviewed, open access journal publishing original research, reports, reviews and commentaries on all areas of sports medicine. The journal is included on PubMed. The manuscript management system is completely online and includes a very quick and fair

Submit your manuscript here: http://www.dovepress.com/open-access-journal-of-sports-medicine-journal

peer-review system. Visit http://www.dovepress.com/testimonials.php to read real quotes from published authors. 